\title{
GENITAL TRACT TUBERCULOSIS AMONG INFERTILE WOMEN: LAPAROSCOPIC EVALUATION
}

\section{Mohamed Nezar*, Kamal Anwar*, Mohamed El-Negery*, Miasa El-Saied**, Rafaat A. Fattah*, Hosam Goda* and Ali A. Wahab***}

Obstetrics \& Gynecology*, Clinical Pathology ** and Pathology *** Departments, Faculty of Medicine, Mansoura University, Egypt.

\section{ABSTRACT}

Objective : To estimate the incidence of genital tract tuberculosis (T.B.) among infertile women during laparoscopic evaluation for infertility in Mansoura University Hospital.

Design : A prospective study.

Setting : Obstetrics \& Gynecology, Pathology and Clinical Pathology Departments, Faculty of Medicine, Mansoura University.

Methods : Two hundreds and ten infertile women were evaluated by laparoscopy for infertility problem from January 2002 to September 2004. Any suspicious findings for T.B. adnexitis or peritonitis were biopsied, and whole endometrial curettage was taken for histopathology. A confirmatory lest P.C.R. was performed form peritoneal fluid samples and tissue biopsics.

Results : The incidence of genital tract T.B. as diagnosed by laparoscopy and confïrmed by tissue biopsy was $5.7 \%$ among infertile women in Mansoura University Hospital. Laparoscopic findings and direct tissuc biopsy had the highest sensitivity and specificity (92-94\%) followed by P.C.R (83-85\%) and lastly endometrial biopsy (75-80\%) for diagnosis of T.B.. The incidence of T.B. increased among rural, low socioeconomic and low educational level patients. Conclusion : Genital T.B.has still a role in the aetiopathogenesis of infertility in our community. Laparoscopy and direct tissue biopsy is the gold standard for diagnosis.

Key words : Genital tract, tuberculosis, infertility, laparoscopy.

\section{INTRODUCTION}

Tuberculosis (T.B.) remains a major health problem in many developing countries and in these areas genital T.B. is present in a significant proportion of females presenting with infertility. However, genital T.B. more particularly has been steadily declining in developed countries ${ }^{(1)}$. World Health Organization "WHO" in 1996 estimated eight millions new cases of T.B. annually (2).

It is estimated that $5-10 \%$ of infertile females all over the world have genital T.B., although this varies from less than $1 \%$ in the United States to nearly $13 \%$ in India ${ }^{(3)}$. Classically, female genital T.B. has been described as a disease of young women, with $80-90 \%$ of patients first diagnosed between the ages 20 and 40 years ${ }^{(4)}$.

The infectious agent in T.B. is usually Mycobacterium T.B,; occasionally Mycobacterium bovis may cause human disease. The Mycobacterium is an obligator aeroba with a replicating cycle on the order of 17-24 hours and

Corresponding author : Mohamed Nezar, Assistant Prof. of Ob/Gyn, Faculty of Medicine, Mansoura University, 
characterized by the acid-fast staining. Genital tract T.B. is almost always secondary to T.B. elsewhere; primary genital T.B. is extremely rare ${ }^{(3)}$.

The fallopian tube constitutes the initial focus of genital T.B. in $90-100 \%$, followed by the uterus in $50-60 \%$, ovarian $20-30 \%$, cervix $5-15 \%$ and vagina $1 \%(3)$.

Genital tract T.B. is an extremely indolent infection. The disease may not become manifest for more than 10 years after initial seeding of the genital tract. The chief presenting complaint of young women with genital tract T.B. is infertility followed by vaginal bleeding and chronic lower abdominal or pelvic pain ${ }^{(3)}$.

The diagnosis of genital tract T.B. is suspected among women with a past history of or treatment for extragenital T.B., chest X-ray with evidence of healed pulmonary T.B. and tuberculin test will yield positive findings. Hysterosalpingography may show characteristic changes suggestive of T.B. infection including beading, sacculation, sinus formation and a rigid "pipestem" pattern of the fallopian tubes ${ }^{(5,6)}$.

Diagnosis can be confirmed by histological examination that reveals typical granuloma, or acid-fast stain and culture of surgical biopsy by laparoscopy or endometrial biopsy specimens ${ }^{(7)}$. Also, there have been recent reports of studies utilizing mycobacterial purified protein antigens in enzyme-linked immunoabsorbent assays (ELISAs) and pylomerase chain reaction ( $\mathrm{PCR}$ ) which are of value in diagnosing T.B. ${ }^{(8,9)}$.

\section{OBJECTIVE}

To estimate the incidence of genital tract T.B. among infertile women and to test the value of laparoscopy in its diagnosis.

\section{MATERIALS \& METHODS}

Two hundred and ten infertile women were studied at Obstetrics \& Gynecology, Pathology and Clinical Pathology Departments, Faculty of Medicine, Mansoura University during the period of January 2002 to September 2004.

The cases included in this study were: female infertile women aged between 20-40 years in whom basic infertility work up: semen analysis, hysterosalpingography "HSG", and day 21 serum progesterone were carried out and referred for laparoscopy.

The data collected in this study were: personal history, medical history in particular history or treatment of extragenital T.B, and results of physical examination. Once the case was recruited to the study, she was examined by a clinician, general and local pelvic examination for any abnormal adnexal mass or tenderness.

\section{Laparoscopy}

Laparoscopy was performed for every case for detection of T.B. criteria, which include: Pallor of the tissues, retort shaped tubes, salpingitis isthmica nodosa "at proximal part of the tube", eversion of fimbrial end of the tube, or distal tubal obstruction and scattered caseating material on pelvic peritoneum or genital tract. Biopsy was taken from any suspected lesion.

Histopathology and laboratory examinations for any suspected case with T.B:

1- Histopathology of any suspected lesion taken by laparoscopy or endometrial biopsy.

2- P.C.R. for peritoneal fluid \& tissue biopsy for detection of specific DNA genomic sequence: P.C.R technique for detection of 
mycobacterium tuberculosis. The size of amplification product obtained is $123 \mathrm{bp}$. "Hispano Lab. Carretra N-1, km 16, 200-28100 Alcobenraf, Madrid Espen".

\section{RESULTS}

The incidence of genital tract T.B. is "5.7\%" (12 cases), 8 cases were housewives from rural areas.

- Table (I) Patient characteristics as regard age, residence, education and occupation.

- Table (II) Determination of strength of association between positive tissue biopsy and other diagnostic tool.

- Table (III) : Clinical data of diagnosed cases having genital T.B.
- Figure (1): Receiver operating characteristic curve (ROC) for studying sensitivity, specificity of different diagnostic parameters for diagnosis of T.B. Laparoscopy and direct tissue biopsy had the highest sensitivity and specificity (92-94\%) followed by P.C.R. (83-85\%) and endometrial biopsy (75-80\%).

- Figure (2): Laparoscopy showing scattered T.B. tubercles on genital tract and pelvic peritoneum "proved by histopathology".

- Figure (3): Laparoscopy showing granulomas on genital tract "proved bilharziasis by histopathology".

- Figure (4): Tuberculous endometritis with granulomatous inflammation containing multinucleated gaint cells.

Table I : Patients characteristics as regards age, residence, education and occupation .

\begin{tabular}{|c|c|c|}
\hline \multicolumn{1}{|c|}{ Variable } & No. & $\%$ \\
\hline Age group (years) & & \\
$(20-24)$ & 14 & 9.1 \\
$(25-29)$ & 50 & 23.8 \\
$(30-34)$ & 86 & 40.9 \\
$(35-40)$ & 55 & 26.2 \\
\hline Residence & & 42.9 \\
Urban & 90 & 57.1 \\
Rural & 120 & 47.6 \\
\hline Educational level & 100 & 5.7 \\
Not educated. & 12 & 38.1 \\
Primary & 80 & 8.6 \\
Middle & 18 & \\
College & & 62.4 \\
\hline Occupation & 131 & 32.4 \\
Housewife & 68 & 5.2 \\
Worker & 11 & \\
High education & & \\
\hline
\end{tabular}


Table II : Determination of strength of association between positive tissue biopsy and other diagnostic tools (odds ratio) .

\begin{tabular}{|l|c|c|c|}
\hline \multicolumn{1}{|c|}{ Variable } & No. (\%) & Odds ratio & 95\% C.I \\
\hline $\begin{array}{l}\text { Positive laparoscopy confirmed by } \\
\text { tissue biopsy }\end{array}$ & $11 / 12$ & 718.6 & $69-74.84$ \\
\hline Positive P.C.R. & $9 / 12$ & 594 & $56-62.89$ \\
\hline Positive Endometrial biopsy & $7 / 12$ & 396 & $39.6-39.59$ \\
\hline
\end{tabular}

C.I $=$ confidence interval

Strength of positivity of different diagnostic tests for diagnosis of T.B. better by laparoscopy and direct tissue biopsy, followed by P.C.R. then endometrial biopsy.

Table III : Clinical data of diagnosed cases having genital T.B. (12 cases) .

\begin{tabular}{|l|c|c|}
\hline \multicolumn{1}{|c|}{ Clinical data } & No. & $\%$ \\
\hline 1- History of night fever \& sweating & 2 & $16.66 \%$ \\
\hline 2- History of pulmonary T.B. & 4 & $33.4 \%$ \\
\hline 3- Abnormal uterine bleeding & 3 & $25 \%$ \\
\hline 4- Adnexal mass & 1 & $8.3 \%$ \\
\hline 5- Anti T.B. drugs & 2 & $16.66 \%$ \\
\hline
\end{tabular}

\section{DISCUSSION}

In this study, the average age of the patients with genital tract T.B. ranged from 20-40 years. This is in agreement with Schaffer et al. (1976) (4) and Jones et al. (1988) ${ }^{(3)}$ who found that female genital T.B is a disease of young women with $80-90 \%$ of patients first diagnosed between the ages of 20-40 years. Also, Sutherland (1983) ${ }^{(10)}$, in a series of 204 patients encountered from 1951 to 1980 , found that the average age at diagnosis ranged from 25-38 years.

In our study the incidence of genital tract T.B. $(5.7 \%)$ increased in patients in rural areas, housewives and among low socioeconomic standards. The incidence of genital tract T.B. in the world (range form $5-10 \%$ ranging from $1 \%$ in United Stated to $13 \%$ in India) with high incidence in India, Scotland and Scandinavia ${ }^{(3,4,10)}$.

The high incidence of genital tract T.B. infection among infertile women in rural areas in the present study especially housewives where economic development and public health conditions are poor. Women's educational levels are very low and some women have no knowledge about health care. They do not know what they should do, and how they can do in the particular time. A few clinics had simple and crude medical 
equipments. These, of course, lead to increasing the chances of T.B. infection $(3,11)$.

As shown in table (II), the diagnosis of genital T.B. is better by laparoscopy and direct tissue biopsy followed by P.C.R. and finally endometrial biopsy. Negative endometrial biopsy does not rule out pelvic involvement with T.B., since sampling errors are common and there may be disease in other genital parts without an associated T.B. endometritis. Therefore, laparoscopic evaluation and biopsy from suspicious areas of internal organs "tubes, ovaries and peritoneum" show high incidence of T.B. of genital tract than endometrial biopsy. Fulk et al. (1980) ${ }^{(12)}$ found that a positive endometrial tissue in approximately $50 \%$ of cases of genital tract T.B., so, laparoscopic evaluation of infertile women to rule out or to diagnose T.B. of the genital tract is very essential. The gold standard in diagnosis of genital tract T.B. is finding characteristic caseating granulomas in biopsy.

T.B. was suspected during laparoscopy in one case but the tissue biopsy proved this case to be due to bilharziasis.

P.C.R. is a technique that can be used to amplify extremely small amounts of a specific DNA genomic sequence, however, the P.C.R. does not distinguish live from killed organisms. So, patients receiving therapy may remain P.C.R. positive for a time despite mycobacterial sterilization. It may be used to support clinical and histological diagnosis of atypical cases of culture negative ${ }^{(8,9,13,14)}$.

In conclusion: The incidence of genital tract T.B. among infertile women is increasing "5.7\%" and increased among rural, low socioeconomic and low educational level patients. Laparoscopy is essential for diagnosis of genital tract T.B. and the sensitivity for documentation of T.B. increased after laparoscopic findings. Negative endometrial biopsy does not rule out T.B. Genital. T.B. has still a role in the aetiopathogenesis of infertility in our community. Prevention of female genital T.B. through a wide spread population vaccination against T.B. will help decrease the number of women with infertility associated with genital T.B.

\section{REFERENCES}

1- Jahromi BN, Parsanezhad S. Shilazi RG: Fernalc genital tuberculosis and infertility. Int J Gynecol Obstet 2001,75: 269-272.

2- Global Tuberculosis Program. In: Global tuberculosis control. WHO; report 1998. Geneva: World Health Organization 1998:237.

3- Jones HW, Went AC, Burnct LS: Novak's Textbook of Gynaecology. Baltimore, MD: Williams \& Wilkins 1988: 557-569.

4- Schaefer G: Female genital tuberculosis. Clin Obstet Gynccol 1976; 10:232.

5- Anthony FJ: Identification and management of tuberculosis. Am Fom Physician 2000, 60: 2667-2681.

6- Raut VS, Mahashur AA and Sheth SS: The Mantoux test in the diagnosis of genital tuberculosis in women. Int J Gynecol Obstet 2001; 72: 165 -169.

7- Quershi RN, Samad S. Hamid R. Laka SE: Female genital tuberculosis revisted. J Pak Med Assoc 2001; $51(1): 16-8$ :

8- Moussa OM, Eraky I, El-Far MA, Osaman HG and Ghoneim MA: Rapid diagnosis of genitourinary tuberculosis by polymerase chain reaction and non-radioactive DNA hybridization. J Urol 2000; 164(2): 584-8.

9. Honore BS, Vincensini JP, Giacuzzo V, Lagrange PH and Herrmann JL: Rapid diagnosis of extrapulmonary tuberculosis by PCR: impact of sample preparation and DNA extraction. J Clin Micro 2003; 41 (6): 2333-9.

10- Sutherland AM: The changing pattern of tuberculosis of the female genital tract: a thirty-year survey. Arch Gynecol 1983; 234: 95.

11- Varma T: Genital tuberculosis and subsequent fertility. Int J Gynec Obstet, 1991; 35; 1-11.

12- Falk V, Luduiksson $\mathrm{K}$ and Agreen G: Genital tuberculosis in women; analysis of 187 newly diagnosed cases from 47 Swedish hospitals during the ten-year period 1968 to 1977. Am J Obstet 
Gynecol 1980; 138:933.

13- Rakha EB: Genital tubelculosis and infertility at Mansoura Hospitals. Master Degree Thesis. Fac Med Mansoura University 2002.

ROC Curve

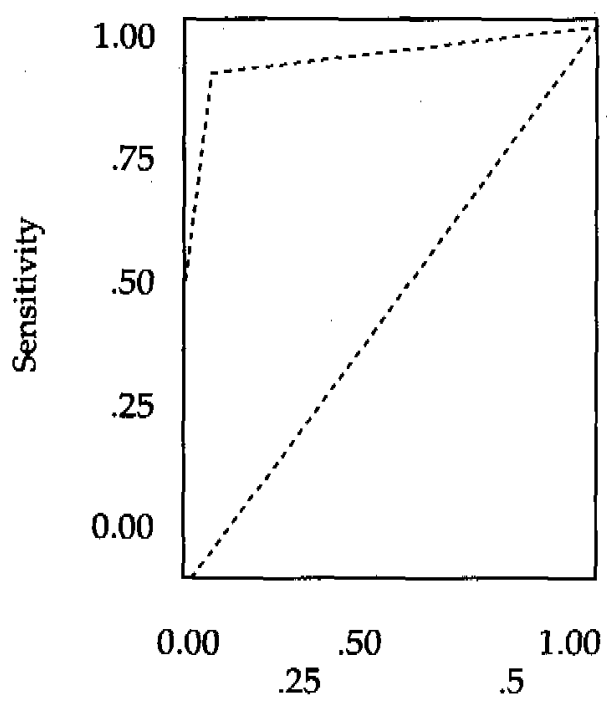

1- Specificity laparoscopy \& direct

tissue biopsy
14- Katsidaze VA, Khosiashvili GZ and Chigogidze TG: Detection of mycobacterium $\mathrm{TB}$ in patients with urogenital TB by PCR method (abstract) in Russian Georgian Med New 2005; (2): 14-7.

ROC Curve

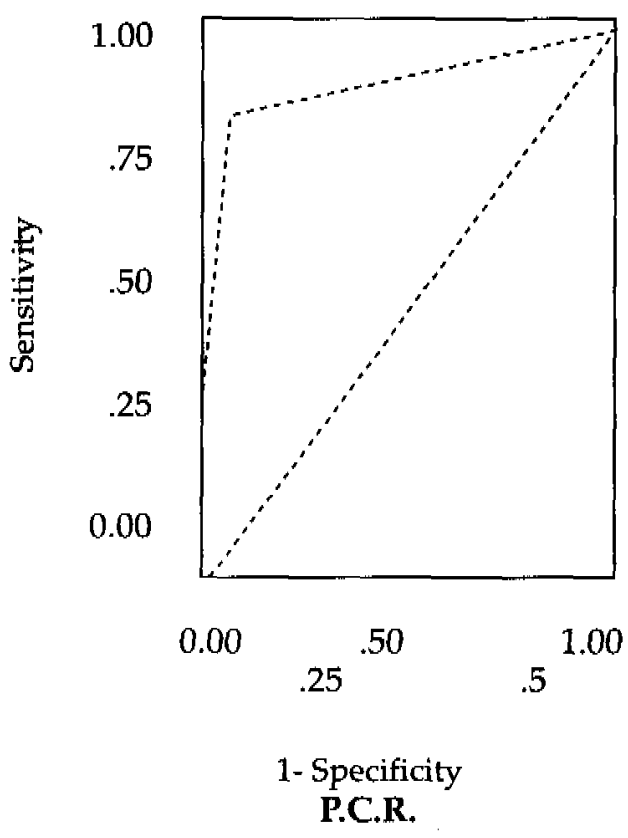

(A)

(B)

\section{ROC Curve}

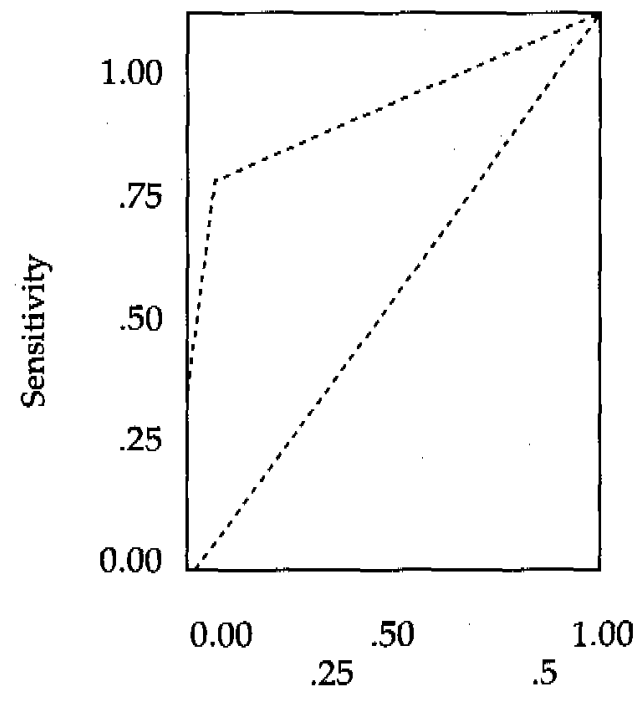

1- Specificity

Endometrial biopsy

(C)

Fig. 1. Receiver operating characteristic curve (ROC) for studying sensitivity, and specilicity of different diagnostic parameters for diagnosis of T.B. 



Fig. 2. Laparoscopy showing scattered T.B. tubercles on the genital trat and pelvic peritoneum "proved by histopathology".
Fig. 3. Laparoscopy showing granulomas on genital tract "proved bilharziasis by histopathology"
Fig. 4. Tuberculous endometritis with granulomatous inflammation containing multinucleated giant cells. 